\title{
EXPERIÊNCIA, ESPAÇO URBANO, POBREZA: CONSTRUINDO ALGUMAS QUESTÕES
}

\section{Thaís Troncon Rosa}

Instituto de Arquitetura e Urbanismo da Universidade de São Paulo / FAPESP thaisrosa@yahoo.com.br

\section{Resumo}

O questionamento sobre as possibilidades de configuração de uma efetiva experiência urbana para indivíduos em situação de pobreza é o mote deste trabalho, fruto de uma pesquisa de doutorado em andamento. Nesse sentido, procura acercar-se da polissêmica noção de "experiência" a partir de duas perspectivas distintas: a de Walter Benjamin, configurada em pleno auge da modernidade, e a de Michel Foucault, cujas últimas elaborações se fizeram em meio às discussões sobre a chamada "pósmodernidade". Tendo em vista as tentativas, contemporâneas, de reconstrução e ressemantização da experiência, o trabalho procura algumas linhas de fuga que auxiliem na reflexão sobre as possíveis relações entre experiência, espaço urbano e pobreza.

\section{Palavras-chave}

Experiência, Espaço urbano, Pobreza

\begin{abstract}
The question on the possibilities of setting up an effective urban experience for individuals in poverty situation is the motto of this paper, the result of an ongoing doctoral research. In this sense, approaches the polysemic notion of "experience" from two different perspectives: that of Walter Benjamin, set in full height of modernity, and Michel Foucault, whose last formulations were made in the midst of discussions about the called "post-modernity". Considering the attempts, contemporaneous, on reconstruction and resemantization of experience, this paper seeks a few lines of flight that could help in reflecting on the possible relations between experience, poverty and urban space.
\end{abstract}

\section{Keywords:}

Experience, Urban space, Poverty 


\section{Modernidade e a experiência em crise}

A reflexão sobre a experiência - palavra polissêmica e conceito polifuncional desempenha papel central no contexto das ciências humanas e sociais e acumula uma grande e controversa fortuna crítica, seja tratando da experiência social (tal como foi formulada a questão desde os primórdios da sociologia); seja tratando das possibilidades de conformação de uma experiência coletiva (de classe, como categoria apriorística, em Marx, ou que conformaria, processual e historicamente, uma classe, em Thompson); seja, ainda - e esta é a perspectiva que me interessa abordar nesta seção do artigo - do encolhimento da experiência na modernidade, do lugar das experiências individuais e de suas articulações a destinos sociais (como encontrada, direta ou indiretamente, em Simmel, Benjamin, Hannah Arendt e Adorno), dentre tantas outras abordagens. Em grande medida, as reflexões sobre a experiência articulam-se à questão da emancipação humana, colocada no centro do pensamento sobre a modernidade, a racionalidade moderna e as formas de dominação dela decorrentes (CAMARGO, 2007).

$\mathrm{Na}$ passagem do século XIX para o XX, a problematização crítica da experiência do "homem moderno" será recorrente em diversos autores. Tal questão, central na obra de Simmel, ecoará de forma contundente nas reflexões de Walter Benjamin e, de forma menos explícita, também nas de Theodor Adorno e Hannah Arendt, todos pensadores cujas abordagens estiveram profundamente perpassadas por suas próprias experiências individuais frente aos fenômenos da modernidade. Pretendo deter-me, aqui, em alguns elementos da reflexão de Benjamin sobre essa experiência, a partir de alguns fios condutores extraídos da obra de Simmel.

Nela, tais fenômenos da modernidade são materializados na cidade, grande e moderna: "a experiência da cidade grande é a experiência mais completa, ampla e fundamental do moderno" (WAIZBORT, 1999, p. 328). Tomando como base sua própria experiência frente às intensas e velozes transformações ocorridas na cidade de Berlim no início do século XX, Simmel se dedicará a investigar as formas de socialização estabelecidas nesse contexto, enfocando especialmente 0 que caracterizou como "monetarização das relações". Assim, a experiência, em Simmel, aparece mediada pela cidade grande (e pelo dinheiro), interessando-lhe particularmente o problema das relações conflituosas, ali estabelecidas, entre indivíduo e sociedade (interior/exterior, subjetividade/objetividade): a experiência do homem moderno é, para o autor, uma experiência de crise, de tensão, de ambiguidade. 
É também, acima de tudo, uma experiência individual: a cidade, enquanto lócus da modernidade, estimula e constitui um tipo próprio de individualidade, cujo "fundamento psicológico" seria a "intensificação da vida nervosa, que resulta da mudança rápida e ininterrupta das impressões interiores e exteriores" (SIMMEL, 2005, p. 577, 578). A mudança contínua é, portanto, elemento fundamental destacado por Simmel na conformação da individualidade e da experiência do homem moderno: a condição moderna, nesse sentido, caracteriza-se como essencialmente desenraizadora. Tempo e espaço se transformam e, consequentemente, uma nova experiência do tempo e do espaço se redesenha, a partir de novas relações de proximidade e distância físicas e espaciais ${ }^{1}$.

A partir da observação das relações (prenhes de conflitos) entre os homens na vida cotidiana na cidade grande, o caráter essencialmente individual da experiência moderna é percebido por Simmel como um recurso que prenuncia a ideia de "autopreservação" frankfurtiana: frente à violência subjetiva que tem lugar na cidade/modernidade, a reação do indivíduo ao desenraizamento é intelectual, um ajuste calculado, racionalizado ${ }^{2}$ das relações, de modo a evitar o choque (sempre iminente). Sendo a proximidade corporal inevitável, o indivíduo procura garantir uma distância "espiritual" segura, evitando o estabelecimento de relações pessoais aprofundadas.

\begin{abstract}
Enquanto o sujeito se ajusta inteiramente por conta própria a essa forma de existência, a sua autoconservação frente à cidade grande exige-Ihe um comportamento não menos negativo de natureza social. A atitude espiritual dos habitantes da cidade grande uns com os outros poderia ser denominada, do ponto de vista formal, como reserva. (SIMMEL, 2005, p. 582 - grifos meus)
\end{abstract}

Desse processo de adaptação do indivíduo resultam uma hipertrofia do intelecto e uma atrofia das sensibilidades, o que constitui o próprio cerne da experiência moderna: uma experiência pautada pela despersonalização nas relações, pela objetividade e pela indiferença no tratamento das coisas e das pessoas. Decorrência da saturação dos sentidos do indivíduo, do excesso de informações a que estaria submetido, a indiferença seria mesmo, para Simmel, a expressão de um certo ethos próprio da cidade grande, que se conformaria em estilo de vida, em

\footnotetext{
1 Simmel recorre ao exemplo do metrô para discorrer sobre a radical transformação do modo de experiência da realidade que a cidade grande e moderna acarreta, Cf. Waizbort (1999, p. 323).

2 Toda a reflexão de Simmel acerca da modernidade dialoga diretamente com a perspectiva crítica frente à modernidade e à racionalização inaugurada com Weber.
} 
comportamento estilizado, ao qual Simmel (2005) denomina de "caráter blasé".

Tais transformações ocorridas na percepção e sensibilidade do homem moderno, na passagem do século XIX para o XX, serão também problematizadas por Walter Benjamin como uma das características da modernidade que concorreriam para o declínio da experiência (Erfahrung). Refletindo, desde a juventude, sobre a questão da experiência, esta se fará presente, direta ou indiretamente, em boa parte da obra do autor: o próprio Benjamim irá registrar, em correspondência trocada com Adorno em 1940, meses antes de sua morte, a intenção de produzir uma "teoria da experiência", cujas raízes remontariam à sua própria experiência. Bruscamente interrompida tal empresa, pode-se dizer que, ainda que inacabadas, suas reflexões lançaram luzes sugestivas sobre as "relações entre os modos de experiência, a aura, a memória, a tradição e a cidade moderna" (JAY, 2009, p. 388).

Considerando que a "experiência autêntica" é fruto de um processo coletivo que tem na relação entre passado e presente seu eixo estruturador, e na tradição, na memória e na narrativa sua possibilidade de continuidade e comunicabilidade, Benjamin aborda criticamente, em diversos de seus trabalhos, o processo de encolhimento - senão desaparecimento - dessa experiência, o qual seria decorrente da ruptura passado/presente e da redução drástica da experiência do tempo e da sociabilidade operada pela modernidade. De fato, para Benjamim, a distinção entre passado e presente (que julgava em franco colapso no mundo moderno) seria condição sine qua non da "verdadeira experiência", a qual implicaria a capacidade de traduzir os vestígios dos acontecimentos do passado para as recordações do presente, mas também de registrar a distância temporal entre hoje e ontem (JAY, 2009, p. 388).

Sem tal condição, a "experiência autêntica" (Erfahrung) estaria, pois, em crise, sendo reduzida à mera vivência de intensidade momentânea, sem ressonância narrativa (Erlebnis): a distinção entre esses dois tipos de experiência ocuparia lugar central na reflexão de Benjamim.

A primeira, a "experiência em sentido forte" (GAGNEBIN, s/d), refere-se à ideia de uma experiência partilhada, à existência de um mundo comum entre os homens, tendo na transmissão e na transmissibilidade sua condição de permanência, de durabilidade, em que as "vivências individuais podiam ser conjugadas com outras do passado coletivo, por meio de uma narrativa que lhe dava ordem e coerência" (LOPES, 2009, p. 03). Aponta, nesse sentido, para uma dimensão utilitária da narrativa (sabedoria, conselho, moral), vinculada à perspectiva intergeracional da experiência, que residiria na capacidade de ser comunicável, de transmitir conhecimento, de transformar-se em tradição: "resíduos de aprendizagem passada 
que ainda podem comunicar-se e resultar operativos no futuro" (JAY, 2009, p. 380). Tal concepção de experiência é indissociável da linguagem e da memória e pressupõe, portanto, um sujeito uno e integrado em uma "comunidade de vida e de discurso", o qual, a partir da "experiência coletiva", a partir do sentido de pertencimento, constrói uma identidade de si (LOPES, 2009; GAGNEBIN, s/d). Nas palavras de Benjamin (1993b): "Onde há experiência, no sentido próprio do termo, não há cisão entre a memória individual e a memória coletiva".

Já a segunda, a vivência, diz respeito à experiência individual, de caráter estritamente pessoal, que não se vincula a um passado coletivo ou à possibilidade de partilha através da palavra narrada. Trata-se de uma experiência de caráter imediato, que, em decorrência da saturação dos sentidos do indivíduo, não deixa vestígios de emoção e, portanto, não lhe é possível recordar involuntariamente.

Desdobrando as reflexões de Simmel, Benjamin irá refletir sobre tal saturação de sensações do homem moderno nas grandes cidades a partir dos poemas de Baudelaire e da noção freudiana de choque (trauma): o excesso de estímulos e a necessidade constante do indivíduo reagir a eles, de absorvê-los imediatamente, uma vez que se sucedem simultânea e velozmente, configurariam a experiência do choque, caracterizada pela fragmentação e pela desconexão. Vinculando-se à realidade imediata, tal experiência é fugaz e armazena-se nas camadas mais superficiais da consciência, prescindindo da memória, pois não se acumula, sendo em breve substituída por novo acontecimento: ela perde seu sentido comunicável, de intercâmbio entre os homens. Assim, ao homem moderno restaria uma experiência sôfrega do presente, essencialmente individual (e solitária), que seria tratada por Benjamin como vivência ${ }^{3}$ (Erlebnis), em contraposição à noção de experiência (Erfahrung).

Quanto maior for a parte do choc em cada impressão isolada; quanto mais estímulos; quanto maior for o sucesso com que ela opere; e quanto menos eles penetrarem na experiência, tanto mais corresponderão ao conceito de "vivência". (BENJAMIN, 1983, p. 34 - grifos meus).

A reflexão de Benjamin sobre a experiência do choque ganhará contornos ainda mais acinzentados após os horrores da primeira guerra mundial, da qual os sobreviventes retornavam "pobres em experiência comunicável", uma vez que a narrativa nunca conseguiria realmente "dizer a experiência inenarrável do horror"

\footnotetext{
${ }^{3}$ Algumas traduções e interpretações utilizam, ao invés do termo "vivência", a expressão "experiência vivida" ou "experiência sensorial" como significado de Erlebnis. 
(GAGNEBIN, s/d). A ideia de choque ou trauma estaria, portanto, no cerne deste rebaixamento da experiência, uma vez que a experiência do trauma não poderia ser assimilada completamente por palavras, pela linguagem ${ }^{4}$, consolidando uma ruptura irreversível dos laços geracionais que pudessem sustentar qualquer possibilidade de reconstrução da "experiência autêntica", entendida como partilha de memória, palavra, tempo e ação comuns.

Nesse sentido, a modernidade assume, em Benjamin, um caráter melancólico, associado à impossibilidade da memória e da narrativa, ao empobrecimento da experiência, à sua perda de significado num mundo completamente transformado pela barbárie tecnificada das guerras mundiais e pelas mutilações permanentes delas decorrentes. Ao conceber a ideia de uma experiência "genuína" ("experiência em sentido forte"), Benjamin estaria dotando a experiência de um potencial redentor, de um caráter "aurático", uma experiência referente a um mundo de infinita e imanente intensidade (associada, por exemplo, ao olhar infantil inocente) (JAY, 2009). Desta forma, sua concepção está inevitavelmente impregnada da nostalgia de um mundo e uma experiência passada, ligada à tradição, ao estabelecimento de uma comunhão entre homem e natureza, propiciada pela temporalidade do trabalho (artesanato) e da arte (aurática) e, acima de tudo, de um tempo lento, "tempo necessário para a transformação das experiências vividas em experiência coletiva" (LOPES, 2009, p. 04), ou seja, completamente distante de qualquer possibilidade de concretização na modernidade.

Entretanto, para além de lamentar a crise da experiência na modernidade, em algumas de suas obras parece haver uma tentativa de encontrar, na destruição, novas oportunidades, vestígios suficientes para a necessária reconstrução da experiência, indicando que nos restaria "confessar que essa pobreza de experiência não é mais privada, mas de toda a humanidade", encarando-a a partir de um "conceito novo e positivo de barbárie".

Pois o que resta para o bárbaro dessa pobreza de experiência? Ela o impele a partir para a frente, a começar de novo, a contentar-se com pouco, a construir com pouco, sem olhar nem para a direita nem para a esquerda. Entre os grandes criadores sempre existiram homens implacáveis que operaram a partir de uma tábula rasa. (BENJAMIN, 1993b, p. 116)

\footnotetext{
4 Cf. aponta Gagnebin (s/d), haveria uma impossibilidade, para a linguagem e para a memória, de assimilar o choque (o trauma, nas palavras de Freud), "porque este, por definição, fere, separa, corta ao sujeito o acesso ao simbólico, em particular à linguagem".
} 
Desde a conhecida crítica de Adorno, não foram poucos os autores a questionar essa ambivalência em Benjamim. No entanto o autor, em alguns de seus últimos escritos (aí incluídas as cartas trocadas com Adorno acerca de suas críticas à primeira versão do "Livro das Passagens"), reafirma sua perspectiva de que haveria, ainda, alguma possibilidade de experiência no mundo moderno, uma experiência justificadamente histórica, que se reconstruiria a partir de resíduos, de cacos da Erfahrung, ou, em outras palavras, a partir das "possibilidades emancipatórias das novas tecnologias de reprodução" e do próprio declínio da experiência (LOPES, 2009, p. 05; JAY, 2009).

Indo além da poesia de Baudelaire, que representaria o ápice da possibilidade de conversão, pela arte, de vivência em experiência autêntica, Benjamin considerava, como indícios dessa reconstrução em curso, "a memória involuntária em Proust, a refuncionalização brechtiana, sua ênfase no potencial cognitivo do cinema experimental, a Bauhaus, o Cubismo, a descontextualização surrealista" (LOPES, 2009, p. 05). Em seu texto "O narrador", Benjamim também teria esboçado a possibilidade de uma narração a partir das ruínas da narrativa tradicional, uma transmissão a partir das migalhas da antiga tradição, uma possível renovação da memória, o que se configuraria na imagem de um "narrador sucateiro", que se interessa por tudo aquilo que é deixado de lado como algo que não tem significação (sofrimento, pobreza etc.) (GAGNEBIN, s/d).

Tal ambivalência deixa entrever a complexidade assumida pela questão da "experiência" na obra de Benjamin e, todavia, reforça o potencial redentor de que lhe dota o autor, sendo inevitável indagar, com Jay (2009, p. 404): haveria, efetivamente, "uma crise da experiência suscetível de compreender-se em termos genuinamente históricos, que implique a perda de algo que em algum momento existiu?" Seria possível afirmar que as condições apontadas por Benjamin como necessárias para que se concretizasse uma experiência redimida, efetiva, autêntica foram, ou poderiam ser, em algum momento alcançadas?

Qualquer que seja a resposta, a experiência seguiu - e segue - sendo alvo de reflexões e debates intelectuais acalorados, em especial entre pensadores franceses, sejam aqueles agrupados em torno da fenomenologia, ou os do chamado pósestruturalismo. É o caso de Michel Foucault, cujas reflexões serão abordadas a seguir.

\section{A experiência na era dos "pós": sujeito debilitado, experiência-limite, linhas de fuga}

Segundo Lyotard, a experiência seria uma "figura moderna", pelo fato de URBANA, V.4, no5, dez.2012 - Dossiê: Cidades e Sociabilidades - CIEC/UNICAMP 
necessitar de um sujeito, "alguém que fale em primeira pessoa" (LYOTARD, apud. JAY, 2009, p. 419). Suas reflexões sobre a chamada "pós-modernidade" incluíram certa aproximação com a ideia de declínio da experiência levada a cabo pelos frankfurtianos: a experiência, em qualquer de suas formas, estaria em crise terminal, em especial após Auschwitz. Segundo Jay (2009, p. 420), essa ideia era compartilhada por diversos intelectuais franceses de uma mesma "geração fenomenológica, a qual chegou a identificar-se diversamente com o pensamento estruturalista, pós-estruturalista e pós-moderno", e apresentava, em decorrência da dissolução drástica do "eu" integrado e da ênfase na importância constitutiva da linguagem, fortes suspeitas frente à ideia de experiência ou vivência. 0 questionamento da experiência, como possibilidade, decorria da crítica a uma noção forte de sujeito centrado, cuja vida poderia ser narrada de forma coerente.

Entretanto, alguns pensadores ligados a este grupo abandonaram tal suspeita, adotando uma "atitude complexa e, em grande medida, positiva frente ao que denominavam explicitamente experiência" (JAY, 2009, p. 422), entre eles Michel Foucault. Concebendo o sujeito como menos organizado e integrado, um "eu" disperso e fragmentado, que resiste a ser apreendido pela reconstrução narrativa, tais pensadores se aproximariam de uma noção de experiência bastante diversa daquela pautada na presença de um sujeito unificado, integrada a uma narrativa, revestida de um caráter aurático: a experiência seria, ao contrário, algo que debilita o sujeito, que o expõe a seus limites, que o abala, por ser, ela mesma, o enfrentamento da "perda de sentido" desse sujeito. Em outras palavras: uma experiência oriunda justamente do processo de desconstrução do sujeito.

As reflexões de Georges Bataille (1992) sobre o que denominou "experiência interior" teriam sido decisivas para a conformação dessa abordagem "pósestruturalista" da experiência, tendo sido referência importante para as elaborações de Foucault. É a partir de sua reflexão que se coloca a ideia da própria experiência como perda, quiçá como sacrifício: uma experiência compreendida muito mais como algo que se sofre ou que se suporta (relação interior-exterior), do que como algo que se alcance por uma práxis ou uma ação meramente individual. Tal concepção significava, portanto, "debilitar o sujeito coerente da experiência", a qual deixa de ser encarada apenas da perspectiva ("fenomenológica") de dentro do sujeito, incorporando, também, uma perspectiva ("sociológica") de fora do mesmo: para o autor, a experiência existiria apenas como relação, como rede de comunicações, não dizendo mais respeito, inteiramente, apenas ao sujeito. Não haveria, portanto, experiência fora de uma "comunidade", entendida como efervescência heterogênea, 
simultaneamente unida e cindida por seus limites: "os limites, especialmente o limite extremo que é a morte do indivíduo, forjam o caráter imanente de uma comunidade e a mantêm cindida por meio de fissuras" (JAY, 2009, p. 432-435). A ideia de limites e de sua transgressão estaria no cerne mesmo da noção de "experiência interior".

Na obra de Foucault, desde "História da Loucura" até seus últimos escritos, a utilização do termo "experiência", de maneira não despropositada, é bastante recorrente, chamando a atenção de diversos de seus comentadores (NICOLAZZI, 2004). O autor desdobrou concepções alternativas acerca da experiência, sendo possível identificar abordagens distintas em algumas "fases" de sua produção intelectual. Ainda que suas primeiras obras tenham tido grande influência fenomenológica, já em "A Arqueologia do Saber" o próprio autor irá questionar a concepção de experiência presente em "História da Loucura" e, desde então, sua abordagem lançará suspeitas sobre a ideia de vivência fenomenológica, que encarava como uma experiência vivida, pré-reflexiva, próxima da Erlebnis alemã. Será, entretanto, em suas últimas obras que Foucault desenvolverá suas análises acerca do que ele próprio apontou como sua "preocupação permanente": "as relações entre o sujeito, a verdade e a constituição da experiência" (FOUCAULT, 1984a, p. 01-02).

Leitor e amigo de Bataille, é forçoso notar que alguns matizes da concepção de experiência desenvolvida por Foucault são tributários da ideia de "experiência interior" desenvolvida por aquele autor, sobre a qual Foucault refletiu como sendo uma experiência do impossível, de uma condição-limite. Contrariando a perspectiva estruturalista, que advogava por uma oposição entre linguagem e experiência, sua interpretação sobre a "experiência interior" considerava uma interpenetração entre experiência e linguagem, mas uma linguagem não-discursiva, em que a subjetividade - "uma autoconsciência integrada e inteiramente interior a si mesma - estava erosionada por completo" (JAY, 2009, p. 445, 446). Para Foucault, "ao converter-se no discurso da transgressão do limite, da subjetividade rota" (FOUCAULT, Apud. JAY, 2009, p. 446), a experiência como que se recobraria, assumindo novos significados.

De fato, desde "História da Loucura", a ideia de "experiência-limite" ${ }^{5}$, tão cara a Foucault, se fará presente. Já nessa obra o autor teria buscado "interrogar uma cultura sobre suas experiências-limite, questioná-la, nos confins da história, sobre um

\footnotetext{
${ }^{5}$ Em entrevista concedida em 1979, Foucault, instado a diferenciar a experiência fenomenológica daquela concebida pelos pensadores que o influenciavam (Nietzche, Maurice Blanchot, Georges Bataille), apontou que enquanto a fenomenologia procurava descobrir na experiência diária um sujeito integrado, transcedental, aqueles pensadores conferiam à experiência "a tarefa de arrancar o sujeito de si mesmo", encarando-a como uma "operação desubjetivante, a idéia de uma 'experiência limite'" que transforma este sujeito em um outro completamente distinto, podendo chegar a sua aniquilação, a sua destruição (FOUCAULT, apud. JAY, 2009, p. 450).
}

URBANA, V.4, no5, dez.2012 - Dossiê: Cidades e Sociabilidades - CIEC/UNICAMP 
dilaceramento que é como o nascimento mesmo de sua história" (FOUCAULT, 1999, p. 142). Admitindo a experiência como "fundadora e condição da história" (NICOLAZZI, 2004, p. 103), o questionamento acerca de como se constitui historicamente a experiência se fará presente em diversas de suas obras: esta seria concebida como um dado cujas condições de possibilidade devem buscar-se em um a priori histórico. Entretanto, como destaca Jay (2009, p. 447), a experiência, em Foucault, não se reduziria por completo à questão de suas "condições de possibilidade" (fossem elas as regularidades discursivas presentes em diferentes épocas históricas, ou os aparatos de poder que as sustentavam), tal como é possível apreender em sua obra final ("História da Sexualidade"): ao centrar-se na constituição do sujeito do saber, a ideia de experiência resiste a ser reduzida a essas condições; ao contrário, deve ser entendida como "a correlação, numa cultura, entre campos de saber, tipos de normatividade e formas de subjetividade" (FOUCAULT, 1984c, p. 10).

Nesse ponto, alguns comentadores de Foucault identificam uma espécie de ambiguidade, uma tensão entre, ao menos, duas versões de experiência presentes em sua obra, com relação à experiência do sujeito - algo que aparece como diferenciado tanto do saber como do poder, e mesmo anterior à sua correlação a eles. Se, inicialmente (em "A Arqueologia do Saber", em especial), sua reflexão esteve pautada por um entendimento da experiência como um a priori, independente de um sujeito específico - este apenas assumiria uma posição, em meio a formações discursivas anônimas, destacadas das experiências subjetivas dos indivíduos (NICOLAZZI, 2004) aos poucos, sua perspectiva incorporará (a partir dos anos 70 e até o fim de sua obra) uma maior correlação entre experiência e subjetividade, a tal ponto que Foucault afirmará ser a experiência a "racionalização de um processo, ele próprio provisório, que termina num sujeito ou em vários sujeitos" (FOUCAULT, 1984d, p. 137).

Em tal perspectiva, a experiência reflexiva ${ }^{6}$ aparece como um elemento central no desenvolvimento da autoconstituição do sujeito: este não existiria como um a priori, mas apenas como resultado do processo de reconhecimento em que consiste a subjetivação (JAY, 2009, p. 449). Em outras palavras, se "o ser se constitui historicamente como experiência" (FOUCAULT, 1984c, p. 12), a experiência seria o "processo no qual, segundo determinadas condições históricas, dá-se um fenômeno cuja construção é simultânea à constituição daquele que age enquanto sujeito" (NICOLAZZI, 2004, p. 122).

\footnotetext{
${ }^{6}$ Embora se realize no presente, a experiência só passa a existir efetivamente depois de ser realizada, pressupondo uma elaboração reflexiva por parte do sujeito: "A experiência não é verdadeira nem falsa; é sempre uma ficção, algo construído que existe somente depois de ter sido feita, não antes. Não é algo que seja 'verdadeiro': é algo que foi uma realidade" (FOUCAULT, apud. JAY, 2009, p. 450).
} 
Não há, entretanto, conforme já apontado anteriormente, uma concepção unificada do sujeito em Foucault. $E$, se o sujeito não é uno, também a experiência não o é: Albuquerque Jr. (2002) aponta mesmo, como uma característica da abordagem de Foucault, a fragmentação da experiência. De fato, Foucault (1984c) irá refletir a partir de "regiões de experiência", "eixos de experiência", denotando um campo múltiplo - fragmentado? - de possibilidades de configuração da experiência e, simultaneamente, do sujeito. Conforme sugere Nicolazzi (2004), não há, na obra de Foucault, origem fundadora da subjetividade ou do sujeito; não se vê emergir em momento algum, das práticas analisadas pelo autor, um sujeito plenamente constituído; a narrativa não se conclui em um ponto derradeiro, mas apenas indica a direção ao futuro, uma vez que a experiência da subjetividade permanece, e sempre se desloca.

De todo modo, a experiência, em Foucault, deve ser entendida como algo para além do sujeito, que não pode ser reduzido à mera subjetividade; como um campo de força dinâmico, nem totalmente dentro, nem totalmente fora do "eu" (o qual, de todo modo, nunca é prévio à experiência e se nega a ser reduzido seja a suas caracterizações transcendentais ou a seus modos empíricos) (JAY, 2009, p. 452). Esse campo de força parece evidenciar-se em seus estudos sobre a "História da Sexualidade", nos quais a experiência, ainda que intrínseca ao processo de subjetivação, conforma-se em dois âmbitos de relações do sujeito: uma relação consigo mesmo e uma relação social com o grupo.

Tal perspectiva já havia sido explicitada por Foucault em entrevistas concedidas alguns anos antes de sua morte, nas quais, além de trazer à tona a importância da experiência em sua obra, o autor destacava, também, uma dimensão coletiva da experiência (reaproximando-se da abordagem de Bataille), afirmando que a transformação proporcionada por esta não seria somente individual, mas teria também um "caráter acessível a outros", devendo ser, "em certa medida, vinculável a uma prática coletiva e a uma maneira de pensar" (FOUCAULT, apud. JAY, 2009, p. 451). Transcendendo seus momentos de origem e realização, as experiências-limite poderiam - e deveriam - ser acessíveis a uma apropriação posterior (JAY, 2009).

uma experiência é, por certo, algo que alguém tem sozinho; mas que não produzirá todo seu impacto a menos que o indivíduo as oriente para escapar da pura subjetividade, de maneira tal que seja possível a outros - não digo exatamente reexperimentá-la - mas ao menos cruzar-se com ela, ou reconstruí-la. (Idem) 
A despeito de sua vasta produção intelectual e dos variados e densos caminhos percorridos por Foucault ao refletir sobre a experiência como realidade em distintos momentos históricos, seu complexo projeto de investigar "as relações entre o sujeito, a verdade e a constituição da experiência" (FOUCAULT, 1984a, p. 01-02) permaneceu até o fim, conforme palavras do próprio autor, como um emaranhado de problemas que resistiam a ser solucionados (Ibidem). Em Foucault, como em Benjamin, a reflexão sobre a experiência é ambígua e inacabada, atestando a complexidade da questão.

Entretanto, é inevitável constatar que, em Foucault, a experiência recobra sua possibilidade de realização, apesar das condições - e contradições - estabelecidas pela modernidade ou, até mesmo, pela era dos "pós" (pós-estruturalismo, pósmodernidade, pós-história). Não se trata, obviamente, de uma perspectiva "otimista", mas aponta para algumas linhas de fuga que parecem permitir pensar a experiência em nosso tempo para além, exclusivamente, da ideia de sua "destruição", "declínio" ou "crise". Ainda que, como indicado ao final da seção anterior, Benjamin também tenha aberto uma brecha nesse sentido, sua referência permanece sendo uma experiência aurática, vinculada a um tempo passado, cujas condições de possibilidade não se enquadrariam na modernidade, enquanto Foucault, ao contrário, parte das condições de possibilidade de cada momento histórico para buscar alcançar experiências engendradas por práticas específicas.

De todo modo, os caminhos abertos por esses - e inúmeros outros pensadores acerca da experiência cada vez mais têm tido seus fios soltos alinhavados em reflexões contemporâneas: considerando-se o "espaço aberto" pelo "declínio da experiência", tal qual fora lucidamente escancarado por Benjamin, têm sido recorrentes as "tentativas de reconstrução" por parte do pensamento crítico e da produção artística. Muito embora alguns autores venham denominando o tempo presente de "era da experiência", tendo em vista a cada vez mais intensa incorporação da noção de experiência pelas esferas do marketing e do consumo7, há que se ressaltar o deslize semântico operado frente ao conceito: "das esferas fundantes da percepção para a esfera dos motes eficazes para o consumo" (LOPES, 2009, p. 01, 13).

\footnotetext{
7 Conforme esclarece Lopes (2008, p. 07): "agora, o que se consome é a própria experiência, ou seja, emoções, satisfações intangíveis, que produzam reações sensoriais. Donde se falar em 'Economia da Experiência' e 'Marketing da Experiência' como conceitos capazes de, superando a visão tradicional do cliente como um consumidor racional dos benefícios e características de um determinado produto, oferecer-Ihe algo a mais: a sensação que o produto pode provocar."
} 
Nesse sentido, parecem ecoar as angústias de Benjamin: seria ainda possível uma efetiva experiência em nosso tempo? Se sim, qual o caráter dessa experiência? Quais suas condições de realização? Estaria ela acessível a que grupos sociais? E, em se tratando de uma reflexão inserida em uma pesquisa desenvolvida no âmbito da Arquitetura e do Urbanismo: qual o papel desempenhado pelo espaço urbano nesse contexto? Eis algumas das indagações que se farão presentes na última seção deste artigo.

\section{Experiência, espaço urbano, pobreza: indagações inconclusivas}

$\mathrm{Na}$ conjuntura social e artística dos anos 1960, duas perspectivas de "reconstrução da experiência" estiveram em embate, como afirma Lopes (2009, p. 13): uma "autêntica, reivindicada pelos movimentos artísticos" e uma "inautêntica, operada pela lógica sistêmica". Naquele momento, "o apelo ao corpo, ao sensorial, às vivências, à experiência (agora lida, sobretudo, na matriz fenomenológica)" era reivindicado como uma "alternativa à reconstrução espúria proporcionada pela indústria cultural". Da exacerbação desse embate à assimilação de tal reivindicação pelo "sistema", deu-se um processo relativamente rápido: se, inicialmente, a cultura fora transformada em mercadoria, estaríamos agora em uma "nova fase", em que a experiência, ela própria, seria o alvo do consumo.

Nesse contexto recente, não apenas o marketing seguiria ressemantizando a experiência (como apontado anteriormente), mas também o design e a arquitetura, através dos chamados "novos espaços experienciais", nos quais, pelo recurso a tecnologias digitais, "as formas de entendimento do espaço e do tempo (condições da nossa percepção e, portanto, elementos conformadores da experiência humana) ganharam novos contornos" (LOPES, 2009, p. 13). Entretanto, alerta o autor, se tais espaços - e as vivências proporcionadas por eles - poderão conformar "experiências autênticas", representando esforços de resistência à "lógica sistêmica", ainda é uma questão em aberto.

De maneira distinta, mas no mesmo sentido de constituição de "microresistências" a tal lógica sistêmica e à sua materialização na "espetacularização das cidades contemporâneas", o espaço urbano vem sendo acionado como lócus e agente de uma outra perspectiva de reconstrução da experiência em nossos dias: uma "experiência corporal da cidade enquanto prática cotidiana, estética ou artística" (JACQUES, 2008, p. 01). A partir da constatação de que os espaços urbanos contemporâneos tornaram-se "desencarnados", ou seja, deixaram de ser praticados, Jacques (2008, p. 03, 04) defende, aproximando-se da noção situacionista de 
"deriva", que "a experiência urbana mobilizadora de percepções corporais mais complexas poderia ser estimulada por uma prática de errâncias pela cidade", inscrevendo no corpo do indivíduo o registro de sua experiência da cidade (processo denominado pela autora de "corpografia urbana"). Evocando como características dessa experiência urbana corporificada a capacidade de se perder (desorientação, em oposição aos pré-condicionamentos urbanos), a lentidão (como negação do "ritmo veloz imposto pela contemporaneidade") e a corporeidade (relação entre o corpo físico do errante e o corpo da cidade que por ele é experimentada), a autora destaca o caráter voluntário, consciente, crítico da errância - e das corpografias dela resultantes - que estaria no cerne de tal experiência, considerando-a mesmo como base possível de outro pensamento urbano, quiçá até de outro urbanismo, ele próprio "incorporado".

É interessante notar que ambas as perspectivas de reconstrução contemporânea da experiência aqui anotadas depositam no espaço urbano importância fundamental. De fato, como já o identificara Simmel, se a cidade é o lócus privilegiado onde transcorre a vida dos homens, não há como pensar a experiência sem pensar a cidade: com a modernidade, experiência e cidade seriam mesmo indissociáveis.

Mesmo em Benjamin, a despeito de sua constatação acerca do declínio da experiência - o qual estaria, em grande medida, atrelado às transformações materializadas na "cidade grande e moderna" de Simmel -, será nessa mesma cidade que o autor irá encontrar os "cacos" de experiência que poderiam sinalizar para a possibilidade de sua reconstrução. É significativo, em sua obra, o papel desempenhado pelo flaneur - personificado em Baudelaire - através de cujos olhos Benjamin procurará pela sobrevivência do mágico, do absoluto, da experiência, no mundo caído da modernidade ${ }^{8}$. Sua obra deixa entrever o que seria a distinção entre um espaço homogêneo, abstrato, e um espaço significado, experienciado, este último vinculado, em grande medida, à experiência do caminhar, do flanar e, ainda mais, à memória (lugares visitados, significados dos nomes de certos lugares, imagens da infância): é o caso, por exemplo, de sua interpretação das passagens das galerias comerciais do século XIX como sendo passagens por entre camadas de um texto, através das quais se fazia possível descobrir resíduos do arcaico na paisagem da cidade moderna (JAY, 2009, p. 378).

Contudo, há um aspecto das mencionadas perspectivas contemporâneas de

\footnotetext{
${ }^{8}$ Projeto inconcluso de Walter Benjamin, ao qual se dedicou intermitentemente durante a última década anterior ao seu suicídio em 1940. Em 2007 foi publicada uma tradução para o português: (BENJAMIN, 2007).
} 
reconstrução da experiência que parece ser importante problematizar: seja a reconstrução "inautêntica" pelo consumo, sejam as possibilidades mais "efetivas" de reconstrução pela arte, pela arquitetura, pelo corpo errante, todas elas se apresentam, de uma maneira ou de outra, como opções ou buscas conscientes de indivíduos desejosos de "experimentar". O homem em busca de "experiências diferenciadas" (LOPES, 2009) não é um homem qualquer: é um homem que dispõe de determinadas condições sociais e materiais - dinheiro, formação escolar, acesso a informações e espaços específicos, até mesmo uma consciência acerca de uma experiência que se desejaria resgatar. Tratar-se-ia, portanto, de uma possibilidade de experiência acessível apenas a alguns grupos sociais.

Jacques, talvez numa tentativa de escapar a esse suposto risco de estratificação de uma experiência urbana possível, referencia Milton Santos ao tratar dos "homens lentos" (SANTOS, 1994), esclarecendo que, para o autor, estes seriam os homens em situação de pobreza, os quais, ainda que de forma involuntária, praticam cotidianamente a cidade, desenvolvendo uma relação física mais profunda com o espaço urbano. Evidencia, assim, em sua proposição, uma distinção entre tais homens, errantes por necessidade (dentre os quais ela destaca os moradores de rua como aqueles que "efetivamente praticam a cidade") e os que erram "por vontade própria", como forma de "investigação" do espaço urbano, como postura crítica - e, portanto, intelectualizada - frente à "espetacularização das cidades" (JACQUES, 2008, p. 10).

Nesse ponto, caberiam algumas indagações: havendo, pois, vislumbres de experiências urbanas possíveis em nosso tempo, seriam elas acessíveis apenas a determinados grupos sociais, sob condições materiais específicas? Estariam os indivíduos em situação de pobreza privados dessa experiência possível? Em que medida vivências cotidianas da pobreza na cidade configuram-se apenas como sucessões de ajustes e adaptações ou podem constituir uma experiência propriamente dita? A partir da ideia, simmeliana, de que a cidade configura um modo de experiência da realidade, como pensar essa experiência em situações em que a existência vivida (substância própria da experiência e da narrativa, segundo Benjamin) pauta-se pela precariedade e pela necessidade?

Tais questões têm-se feito sensíveis à minha pesquisa de doutorado ${ }^{9}$, tendo

\footnotetext{
${ }^{9}$ Embora tenha optado por não trabalhar com dados empíricos neste trabalho, ao longo desta seção a reflexão estará pautada, indiretamente, em dados obtidos em minha pesquisa de mestrado (ROSA, 2008), em dados publicados de pesquisas com trajetórias urbanas (como, por exemplo, as contidas em TELLES \& CABANNES, 2006) e, sobretudo, em minha pesquisa de doutorado em andamento (ROSA, 2012). Inserindo-se nos debates sobre pobreza e produção do espaço urbano no Brasil e tomando como base a realização de uma pesquisa de campo na cidade de São Carlos - SP, a pesquisa propõe, por um 
em vista que, buscando investigar se existem - e como se dão - os nexos entre mobilidades socioespaciais, deslocamentos habitacionais, dinâmicas familiares e políticas urbanas nos processos de produção e apropriação dos espaços de moradia dos pobres em contextos urbanos não metropolitanos, foi adotado, como estratégia metodológica principal, o estudo de trajetórias urbanas de famílias e indivíduos em situação de pobreza.

A ideia de trajetória é acionada na pesquisa, conforme proposto por Certeau (1994), como um "movimento temporal no espaço": as trajetórias urbanas, portanto, "supõem uma espacialização demarcada pelas temporalidades urbanas corporificadas nos espaços e territórios da cidade" (TELLES, 2006a, p. 70). Condensando práticas espaciais cotidianas (CERTEAU, 1994) dos indivíduos e suas famílias, as quais se constituem tanto através do diálogo permanente entre passado e presente, como da justaposição das dimensões qualitativamente heterogêneas de espaço e tempo, as trajetórias urbanas compreendem percursos habitacionais e ocupacionais, além dos deslocamentos cotidianos que se realizam na articulação entre trabalho, moradia e serviços urbanos. $\mathrm{E}$, se a articulação entre temporalidades (tempos biográficos, geracionais, sociais e históricos) e espacialidades (marcos espaciais, referências urbanas, pontos de condensação dos deslocamentos) é constitutiva da análise de trajetórias urbanas, um terceiro aspecto se entrelaça a elas e faz-se crucial para a metodologia aqui proposta: os eventos políticos que as atravessam, ao operarem como vetores concretos na produção do espaço urbano (TELLES \& CABANNES, 2006).

A partir dessa compreensão das trajetórias urbanas, uma conjetura tem sido constante: a de que não seria possível perscrutar tais trajetórias sem esbarrar na noção de experiência, seja no sentido da articulação entre memória e narrativa, passado e presente, que lhe é inerente (de acordo com Benjamin), seja a partir do seu entendimento como resultado da correlação de saberes, normatividades e subjetividades (conforme Foucault), para citar alguns dos possíveis imbricamentos entre algumas concepções de experiência e a abordagem das trajetórias urbanas.

Se considerarmos que estas se configuram a partir de práticas que delineiam histórias de vida, a perspectiva foucaultiana da articulação entre experiência e

\footnotetext{
lado, identificar e investigar trajetórias urbanas de famílias e indivíduos em situação de pobreza, moradores de periferias urbanas que, nas últimas décadas, venham transitando pela cidade em busca de moradia e trabalho, e, por outro, verificar a articulação entre as dinâmicas socioespaciais apreendidas por meio das trajetórias e as políticas urbanas e habitacionais empreendidas na cidade - ou a ausência delas - nesse mesmo período. A proposta metodológica de seguir etnograficamente trajetórias urbanas de famílias e indivíduos em situação de pobreza busca estabelecer uma mudança na escala de compreensão sobre as já bastante debatidas relações entre pobreza e espaço urbano no Brasil, distanciando-se de designações genéricas para aproximar-se de fluxos, trânsitos, deslocamentos e mobilidades que produzem, sob esta ótica, não configurações urbanas à parte da cidade, senão a própria cidade (e experiências urbanas possíveis).
}

URBANA, V.4, n5, dez.2012 - Dossiê: Cidades e Sociabilidades - CIEC/UNICAMP 
subjetividade pode enriquecer sobremaneira as análises. A dimensão da experiência enquanto indissociável do processo de subjetivação (FOUCAULT, 1984c; SCOTT, 1999) a aproxima de algo ainda realizável, menos intangível: algo a que todos estaríamos suscetíveis, senão independentemente, apesar de condições materiais e inclusive em função de diferenças e desigualdades. A partir das trajetórias, poderia ser possível aproximar-se "da natureza construída da experiência, [...] de como os sujeitos são, desde o início, constituídos de maneiras diferentes" de forma a "explorar como se estabelece a diferença, como ela opera, como e de que forma ela constitui sujeitos que veem e agem no mundo" (SCOTT, 1999, p. 26). A experiência não seria, portanto, privilégio de alguns, nem mesmo poderia ser encarada como algo necessariamente positivo (ou vinculado a uma dimensão aurática, de autenticidade, tal qual proposto pelos frankfurtianos); seria, acima de tudo, um processo que conforma historicamente sujeitos, que torna visíveis suas atribuições de posições, suas mobilidades, suas possibilidades de escolhas.

[...] sujeitos têm agenciamento. Eles não são indivíduos unificados, autônomos, que exercem o livre arbítrio, mas, ao contrário, são sujeitos cujo agenciamento é criado através de situações e posições que lhes são conferidas. Ser um sujeito significa estar "sujeitado a condições de existência definidas, condições de designação de agentes e condições de exercício". Essas condições possibilitam escolhas, apesar de não serem ilimitadas. [...] Experiência é uma história do sujeito. (SCOTT, 1999, p. 42 - grifo meu)

Nesse sentido, em se tratando de trajetórias urbanas da pobreza, algumas linhas de fuga preliminares poderiam ser esboçadas a partir das reflexões estabelecidas até aqui. A começar pela ideia de experiência-limite presente em Foucault - e sua perspectiva de um sujeito "desintegrado" - a qual parece ser útil para pensar o que poderia configurar uma experiência urbana da pobreza. O choque, o trauma, a desterritorialização assumem, nessa ideia, novo sentido: são a própria condição de realização dessa experiência-limite.

De alguma forma, também a ideia de "novos recomeços", tal qual enunciada por Benjamin ${ }^{10}$ (1993a, p. 116) pode abrir uma trilha para se pensar as trajetórias da pobreza na cidade. Conforme discutido anteriormente, a experiência empobrecida se aproximaria de um conceito positivo de barbárie: "Ela o impele a partir para a frente, a começar de novo, a contentar-se com pouco, a construir com pouco, sem olhar nem

\footnotetext{
${ }^{10} \mathrm{E}$ atualizada por Hannah Arendt, ao longo de toda a sua obra.

URBANA, V.4, no5, dez.2012 - Dossiê: Cidades e Sociabilidades - CIEC/UNICAMP
} 
para a direita nem para a esquerda".

De fato, é possível constatar, ao tomar contato com trajetórias urbanas da pobreza, que a sucessão de traumas, de desenraizamentos, de condições-limite a que os indivíduos estão cotidiana - e historicamente - submetidos (sujeitados) não inviabiliza, necessariamente, que se configure um processo de subjetivação, uma elaboração individual e coletiva de tais acontecimentos, uma transformação que é, simultaneamente, desintegração do sujeito e sua reconfiguração em outros possíveis.

Ainda mais se considerarmos, com Simmel, que o sujeito não é unitário: uma parte pode estar "nivelada", e outras podem não estar. O autor sugere que a complexificação/racionalização dos processos e mecanismos de dominação na modernidade, com suas múltiplas relações de interdependência, tenderia a tornar a dominação cada vez menos totalizante. Aparece, nesse sentido, uma noção de liberdade relativa, que se configuraria como o espaço de transição de um estado de constrangimento a outro, sua contínua alteração, quase uma "permuta de contingências". Em Simmel, portanto, a liberdade moderna se aproximaria da ideia de mobilidade: não significa ausência de constrangimentos, mas uma nova maneira de lidar com eles, que supõe um jogo de aproximação e distância entre os indivíduos, bem como seus trânsitos entre as variadas possibilidades de interação na cidade. Essa liberdade potencial estaria articulada à despersonalização das relações de dominação empreendida na modernidade: as teias de dependência dos indivíduos são infinitamente mais múltiplas e, portanto, mais fluidas, mais rarefeitas, quiçá mais permeáveis ${ }^{11}$.

Não se trata, obviamente, de imaginar - ignorando a negatividade do desenraizamento e da desterritorialização que elas encerram - que as trajetórias urbanas da pobreza, ao fazer da mobilidade quase uma estratégia de sobrevivência, guardariam uma maior possibilidade de liberdade. Entretanto, por operarem justamente a partir da chave da mobilidade, as possibilidades de agenciamentos dos sujeitos - e destes com a cidade - se ampliam, ainda que a partir de limitações estruturais, conforme as já mencionadas reflexões de Scott (1999). Nessa perspectiva, talvez fosse possível encarar a possibilidade de configuração de experiências urbanas da pobreza a partir da consideração (deveras visionária) de Foucault (1984b - grifos meus):

\footnotetext{
${ }^{11}$ Cf. notas de aula da disciplina Modernidade e Modernização, ministrada pela prof. Cibele Rizek, cursada no programa de pós graduação em Arquitetura e Urbanismo do Instituto de Arquitetura e Urbanismo de São Carlos no primeiro semestre de 2010. Esta visão poderia ser aproximada da idéia de táticas, presente em Certeau (1994).
} 
Nós vivemos na época da simultaneidade: nós vivemos na época da justaposição, do próximo e do longínquo, do lado-a-lado e do disperso. Julgo que ocupamos um tempo no qual a nossa experiência do mundo se assemelha mais a uma rede que vai ligando pontos e se intersecta com a sua própria meada do que propriamente a uma vivência que se vai enriquecendo com o tempo.

Entretanto, um tensionamento parece operar continuamente no interior dessa trama - espacial - que poderia vir a se conformar como experiência: a relação entre determinações e liberdades (Simmel), entre limites condicionados e possibilidades de escolha (Scott), entre o ajuste à realidade e o desejo de transformação.

Segundo Benjamin, "o desejo pertence às ordens da experiência" (1983, p. 46). Nesse sentido, outra dimensão do "encolhimento da experiência" seria o desaparecimento do desejo como elo de articulação entre presente, passado e futuro:

Na vida, quanto mais cedo se formula um desejo, tanto maiores são as suas perspectivas de realização. Quanto mais um desejo remonta no tempo, tanto mais se pode esperar a sua concretização. Mas aquilo que reporta ao tempo passado é a experiência, é o que o preenche e articula. Por isso, o desejo realizado é a coroa destinada à experiência (BENJAMIN, 1983, p. 46).

A matéria imprecisa e incerta do desejo poderia ser, portanto, o ponto de partida da criação de uma experiência possível, tendo em vista sua capacidade de redimensionar o tempo da vida (ABREU, 1998). Entretanto, em oposição ao desejo, estaria o ajuste, uma relação automática de acordo à realidade, que apareceria como algo inescapável, inelutável. Em uma sociedade que prega "o fim da crença na adequação entre o desejo e a realidade" (LOPES, 2008, p. 11), o real acaba por se configurar como única alternativa, assume positividade, necessidades são naturalizadas: desaparece a dimensão do desejo, ele vira denúncia do seu próprio limite, e isso é negado.

Embora, em se tratando de trajetórias urbanas da pobreza, a dimensão do ajuste possa parecer se sobrepor em definitivo sobre a do desejo, esse contínuo e invisível tensionamento pode ser, por vezes, energia impulsionadora de um desvio, de uma aposta, de uma potência que, em certos casos, manifesta-se espacialmente, seja na produção da moradia (CAVALCANTI, 2007), nas disputas em torno da produção do espaço urbano (ROSA, 2008) ou nas subversões de usos dos espaços públicos ou coletivos (LEITE, 2002), para indicar algumas possibilidades. 
Nesses casos, poderia-se pensar em formas de condensação da própria experiência, espacialização de práticas que se configurariam em contra-espaços (ou "espaços outros", "heterotopias", conforme FOUCAULT, 1984b), momentos mesmo em que experiência e espaço urbano imbricam-se de forma potente? Talvez, e aqui se abre um novo flanco de investigação, o qual não caberia a este trabalho aprofundar.

As reflexões aqui desenvolvidas, mais do que encerrar questões, abrem-se para outras indagações, considerando-se, na persecução de trajetórias urbanas de indivíduos e famílias em situação de pobreza, a experiência possível e sua conformação no espaço urbano: que experiências do espaço urbano têm esses indivíduos, e como elas se conformam subjetiva, coletiva e territorialmente? Como tudo isso se espacializa - experiências, vivências, memórias, desejos? Em que medida esses movimentos de aproximação e distância, esses trânsitos intersubjetivos na cidade configuram espaços? Ou ainda, conforme as provocações de Rizek:

Como pensar hoje - no quadro desses processos de transformações econômicas, sociais, políticas, territoriais, as relações entre cidade, corpo e subjetividade? Será que ainda podemos evocar W. Benjamin e perguntar pela cidade que nos habita e nos constitui, que marca corpos, constrói registros e regimes de sensibilidade? [...] Como pensar a dobra que faz ao mesmo tempo cidades e territórios e subjetividades e sensibilidades? A questão então é a de ler cidades e sujeitos - ou o que sobrou deles - dentro e fora dos equipamentos de poder e de biopoder, nos interstícios, dentro e fora dos regimes que constroem a verdade - o que quer que possamos chamar de verdade e de conhecimento. (RIZEK, 2010)

\section{Referências}

ABRÊU, Eide Sandra Azevêdo. Walter Benjamin e o tempo da Grande Indústria. In: Diálogos - revista do Departamento de História e do Programa de Pós Graduação em História da Universidade Estadual de Maringá, vol. 2, n.1, p. 65-79, 1998. Disponível em

<http://www.dhi.uem.br/publicacoesdhi/dialogos/volume01/vol02_atg2.htm\#_edn2> . Acesso em jul. 2010.

ALBUQUERQUE Jr., Durval Muniz de. Experiência: uma fissura no silêncio. In: Territórios e fronteiras, v.3, n. 1, p. 61-75, 2002.

BATAILLE, Georges. A Experiência Interior. Tradução de Celso Libânio Coutinho et. al. São Paulo: Editora Ática, 1992.

BEnJAMin, Walter. Experiência e pobreza. In: Magia e Técnica, Arte e Política. 
Ensaios sobre Literatura e História da Cultura. Obras Escolhidas. 5.ed. Trad. Sérgio Paulo Rouanet. São Paulo: Brasiliense, 1993a.

- O Narrador. Considerações sobre a obra de Nikolai Leskov. In: Magia e

Técnica, Arte e Política. Ensaios sobre Literatura e História da Cultura. Obras Escolhidas. 5.ed. Trad. Sérgio Paulo Rouanet. São Paulo: Brasiliense, 1993b.

. Passagens (1927-1940). São Paulo: Imprensa Oficial do Estado, 2007. . Sociologia. 2. ed. São Paulo: Ática, 1991.

; HORKHEIMER, Max; ADORNO, Theodor W.; HABERMAS, Jürgen. Textos escolhidos. 2. ed. São Paulo: Abril Cultural, 1983.

BONDÍA, Jorge Larrosa. Notas sobre a experiência e o saber de experiência. In:

Revista Brasileira de Educação, n. 19. Disponível em <http://www.anped.org.br/rbe/rbedigital/RBDE19/RBDE19_04_JORGE_LARROSA_BO NDIA.pdf>. Acesso em out. 2010.

CAMARGO, Sílvio C.. Experiência e Utopia em Theodor W. Adorno, André Gorz e Francois Dubet. In: Em Tese - revista eletrônica dos pós-graduandos em Sociologia Política da UFSC. V. 4, n. 1 (1), ago.-dez., 2007. Disponível em: <http://www.emtese.ufsc.br/vol4_res_art2.pdf>. Acesso em jun. 2010.

CAVALCANTI, Mariana. Do Barraco à Casa: tempo, espaço e valor(es) em uma favela carioca. In: Anais do $31^{\circ}$ Encontro Anual da ANPOCS. Caxambu, 2007.

CERTEAU, Michel de. A invenção do cotidiano: artes de fazer. Petrópolis: Vozes, 1994. FOUCALT, Michel. A arqueologia do saber. Rio de Janeiro: Forense Universitária, 1997.

. De outros espaços. Architecture, Movemente, Continuité, n.5, 1984b. Disponível em <http://www.ufrgs.br/corpoarteclinica/obra/outros.prn.pdf>. Acesso em out. 2010.

Ditos e escritos I. Problematização do sujeito: psicologia, psiquiatria e psicanálise. Rio de Janeiro: Forense Universitária, 1999.

. História da sexualidade II: o uso dos prazeres. Rio de Janeiro: Graal, 1984c.

. O retorno da moral. In: Escobar, C. H. de (Org). Dossier Michel Foucault: últimas entrevistas. Rio de Janeiro: Taurus, 1984d.

. Une esthétique de l'existence. Le monde, 15-16 juillet, p. XI, 1984a. Tradução de Wanderson Flor do Nascimento. Disponível em <http://filoesco.unb.br/foucault/estetica.pdf>. Acesso em out. 2010.

GAGNEBIN, Jeane Marie. Memória, História, Testemunho. Disponível em <http://www.comciencia.br/reportagens/memoria/09.shtml> Acesso em out. 2010. 
Walter Benjamin ou a história aberta. In: Magia e Técnica, Arte e Política.

Ensaios sobre Literatura e História da Cultura. Obras Escolhidas. 5. ed. Trad. Sérgio Paulo Rouanet. São Paulo: Brasiliense, 1993.

JACQUES, Paola Berestein. Corpografias Urbanas. In: Anais do IV ENECULT Encontro de Estudos Multidisciplinares em Cultura. Salvador: UFBA, 2008. Disponível em <http://www.cult.ufba.br/enecult2008/14401-03.pdf> Acesso em nov. 2010.

JAY, Martin. Cantos de experiencia. Variaciones norteamericanas y europeas modernas sobre un tema universal. Argentina: Paidos, 2009.

LEITE, Rogerio Proença. Contra-usos e espaço público: notas sobre a construção social dos lugares na Manguetown. In: Revista Brasileira de Ciências Sociais, vol. 17, n.o 49, junho 2002, p. 115-134.

LOPES, Ruy Sardinha. A experiência: entre a resistência e as estratégias mercadológicas. In: Anais do II Seminário Arte \& Cidade. Salvador: UFBA, 2008.

- O declínio e as reconstruções da experiência na modernidade e na contemporaneidade. In: Arte e Arquitetura: balanços e novas direções. VII Fórum Brasília de Artes. Brasília: Fundação Athos Bulcão, 2009.

MEINERZ, Andréia. Concepção de experiência em Walter Benjamin. (Dissertação) Mestrado em Filosofia. Universidade Federal do Rio Grande do Sul, Porto Alegre, 2008. NICOLAZZI, Fernando. A narrativa da experiência em Foucault e Thompson. In: Anos 90, Porto Alegre, v. 11, n. 19/20, p.101-138, jan./dez, 2004. Disponível em <http://seer.ufrgs.br/index.php/anos90/article/viewFile/6353/3804> Acesso em out. 2010.

OELZE, Berthold; SOUZA, Jessé (Orgs). Simmel e a modernidade. Brasília: Editora UNB, 2005.

RIZEK, Cibele Saliba. Pequenas provocações. In: Caderno de provocações. Corpocidade: debates em estética urbana. Salvador / Rio de Janeiro: UFBA / UFRJ, 2010.

ROSA, Thaís Troncon. Fronteiras em disputa na produção do espaço urbano: a trajetória do 'Gonzaga' de favela a bairro de periferia. (Dissertação) Mestrado em História. Instituto de Filosofia e Ciência Humanas - UNICAMP, Campinas, 2008.

SIMMEL, Georg. As grandes cidades e a vida do espírito. In: MANA 11(2), p. 577$591,2005$.

SIMMEL, Georg. Questões fundamentais da sociologia. Rio de Janeiro: J. Zahar, 2006.

SCOTT, Joan. Experiência. In: SILVA, Alcione da; et al. Falas de Gênero. Florianópolis: Ed. Mulheres, 1999. 
TELLES, Vera da Silva; CABANES, Robert (Orgs). Nas tramas da cidade: trajetórias urbanas e seus territórios. São Paulo: Humanitas, 2006.

TELLES, Vera da Silva. Trajetórias urbanas: fios de uma descrição da cidade. In: ; CABANES, Robert (Orgs). Nas tramas da cidade: trajetórias urbanas e seus territórios. São Paulo: Humanitas, 2006.

WAIZBORT, Leopoldo. A cidade, grande e moderna. In: As aventuras de Georg Simmel. São Paulo: Curso de Pós-Graduação em Sociologia - USP/Editora 34, 2000. 